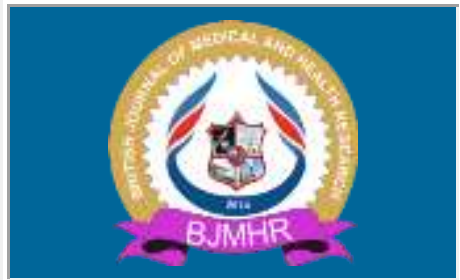

\title{
BJMHR
}

British Journal of Medical and Health Research Journal home page: www.bjmhr.com

\section{Waist-hip ratio, body mass index and risk of chronic medical condition in women aged 30 years and above: a cross-sectional study}

\section{Ibrahim D. A. Sakal ${ }^{1 *}$, Abdalhalim Suaiee ${ }^{2}$, Albasher Alafe ${ }^{3}$, Baled I. Khalefa ${ }^{4}$, Eman Abogela ${ }^{1}$, Mawada Belhaj ${ }^{1}$, Aya Alshomate ${ }^{1}$ \\ 1. Zoology Department, Science Faculty, Sabratha University-Libya. \\ 2. Statistics Department, Science Faculty, University of Zawia-Libya. \\ 3. Zoology Department, Science Faculty, University of Zawia-Libya. 4. Department of Zoology, College of science, Al-Zintan University-Libya.}

\section{ABSTRACT}

The present investigation was undertaken with the aim to study the prevalence and relationship of Waist-Hip Ratio (WHR) and Body Mass Index (BMI) with health risk and their associated socio-demographic correlates in the women. The data was collected from 120 women, aged 30 years and above with a mean age of $47.30 \pm 13.20$ years (range 30 to 88 ). The cross-sectional study conducted in 2019 among Sabratha residents. The participants were assessed with anthropometric measurements including height, weight, BMI, waist circumference, hip circumference and WHR. Respondents provided information on their socio-demographic details and health conditions. Prevalence of those who were obese, overweight, normal and underweight based on BMI was $40.0 \%, 39.2 \%, 18.3 \%$ and $2.5 \%$ respectively. Participants aged 45 years and above were more likely to be overweight and obese compared to those aged 30-44 years. Participants who were none educated were more likely to be overweight compared to complete educated. Participants who were overweight were less likely to have heart problems, while participants who were obese were more likely to have heart problems. Prevalence of those who were high, normal and low based on WHR was $65.8 \%, 4.2 \%$ and $30.0 \%$ respectively. Participants aged 45 years and above were more likely to have high WHR compared to those aged 30-44 years. Participants who were overweight and those with a higher WHR were more likely to have heart problems.

Keywords: WHR, BMI, Chronic Medical Conditions, Women.

*Corresponding Author Email: i.dsakal@yahoo.in

Received 05 April 2020, Accepted 14 April 2020

Please cite this article as: Sakal I et al., Waist-hip ratio, body mass index and risk of chronic medical condition in women aged 30 years and above: a cross-sectional study. British Journal of Medical and Health Research 2020. 


\section{INTRODUCTION}

The proportion of the elderly in the population of the world has been steadily increasing and the life expectancy has increased over the last three decades ${ }^{[1,2]}$. Several changes in the body take place as one ages, namely physiological ageing, which affects body mass and composition even in the absence of diseases ${ }^{[3]}$.

The ageing process involves physiological and nutritional changes that are manifested by height, weight and muscular mass loss and an increase fat accumulation in the trunk and viscera ${ }^{[4-7]}$. Poor energy regulation, reduced hormonal levels and changes in the metabolic rate also resulted the aging process, which in turn affect their anthropometric measurements and risk of cardiovascular diseases (CVD) ${ }^{[8]}$.

Anthropometry provides an indirect evaluation of body composition and risk of acute and chronic diseases. ${ }^{[9,10]}$. The Body Mass Index (BMI) is standard anthropometric measurement tool employed by the World Health Organization (WHO) which uses a ratio of weight and height to classify the weight of the body as underweight, normal, overweight or obese ${ }^{[1]}$. It is an indicator for a number of health risks such as high blood pressure, diabetes and heart diseases ${ }^{[11]}$. BMI has been found to be not a sensitive index to measure obesity and it does not account for variation in body fat distribution and abdominal fat mass, which can differ greatly across populations ${ }^{[12]}$.

The measurements of waist circumference and waist-hip ratio (WHR) have been viewed as alternatives to BMI. Thus, many health foundation recommends these measures as a practical tool to measure risk factors for diseases like diabetes and hypertension ${ }^{[13,14]}$. Many studies in adults have reported a strong positive association between cardiovascular risk factors with measures of waist circumference or WHR instead of BMI alone ${ }^{[15-17]}$.

In Libya, there is a great difference of the socio-demographic status between the populations who live in different parts of the country. This cross-sectional study carried out in Sbratha city, Libya and it was aimed (i) to determine the prevalence of obesity, as well as underweight in the women, (ii) to measure the waist circumference and waist-hip ratio (WHR), (iii) explore the socio-demographic factors which predict the anthropometric characteristics in the women and finally, (iv) explore the relationship between BMI and WHR with chronic health conditions in women aged 30 years and above.

\section{MATERIALS AND METHOD}

\section{Sample Size}

Five hundred and fifty questionnaires were distributed to participants randomly chosen and a total of 120 were included in this study. In the event that participants were unable to do so, a written informed consent was taken from their legally acceptable representative before 
including the respondent in the study. Participants in the study were residents in Sabratha city aged 30 years and above (mean age $47.30 \pm 13.20$ years, range 30 to 88 ).

\section{Data collection}

This cross sectional study was done in Sabratha Teaching Hospital, during the period November 2019 to January 2020. During the initial data collection session, the women's age (30-44, 45-59, 60+), marital status (never married, married, widowed, divorced), education (none, primary (Basic), secondary, completed), employment status (employed, unemployed, homemaker, retired), medical history-namely hypertension, heart problems, diabetes were recorded. Data were collected by researchers at the beginning of working days.

\section{Measures}

\section{Anthropometric measurements}

Height and weight were measured by researchers field interviewers, using a tape measure and digital standing scale which was calibrated before every use.

\section{Body Mass Index (BMI)}

BMI is defined as the weight in kilograms divided by the square of the height in meters $\left(\mathrm{kg} / \mathrm{m}^{2}\right)$. Cut-off standards by the World Health Organization (WHO) were used ${ }^{[18]}$. A BMI of less than 18.5 was classified as under-weight, BMI of 18.5 to 25 as normal weight, BMI of 25.01 up to 30.0 was classified as overweight and BMI of $>30.0$ was classified as obese.

\section{Waist circumference}

The circumferences were measured to the nearest centimeter using a flexible tape with the respondent standing. In women, the abdominal circumference (waist) was measured as the narrowest part of the body between chest and hips.

\section{Hip circumference}

The participant's hip circumference was measured as the maximum circumference around the buttocks posteriorly at the level of greater trochanters (hip bones) and measured in centimeters.

\section{Waist to Hip Ratio (WHR)}

WHR was determined by dividing waist circumference by hip circumference. WHO [18] recommends cut-off points for waist circumference and WHR as $80 \mathrm{~cm}, 0.80$ for women respectively, where a higher ratio indicates an increased risk of various health complications.

\section{Statistical Analysis}

Descriptive and inferential statistics were used to analyze the data including mean, standard deviation, multinomial logistic regression, odds ratio and Wald's Chi-Square test. The significance level $(\alpha)$ for the analyses was sat at $(0.05)$; $95 \%$ confidence intervals were presented. The Statistical Package for Social Sciences (SPSS, 23) was used for the analyses. 


\section{RESULTS AND DISCUSSION}

A total of 120 participants completed the study, yielding a response rate of $22 \%$. The overall prevalence of obesity and overweight was $40.0 \%$ and $39.2 \%$ respectively while underweight was $2.50 \%$. The prevalence of normal BMI was $18.3 \%$. Table 1 shows the weighted proportions of BMI and WHR category in the study sample as well as among the different socio-demographic groups.

Multinomial logistic regression analyses revealed that participants aged 45 years and above were more likely to be obese than those aged 30-44 years. A comparison among the Education groups showed that participants who were not educated were more likely to be overweight compared to those who were complete educated. participants who were retired were more likely to be obese compared to those who were employed. WHR across the socio-demographic groups is shown in Table 2. The prevalence of high WHR in our sample was $65.8 \%(n=79)$. Multiple logistic regressions showed that participants who aged 45 years and above were more likely to have high WHR than those aged 30-44. Other socio-demographic groups like marital status were not significantly related to BMI and WHR (Table 2).

In multiple logistic regression, we found that those who were overweight were more likely to have heart problems $(\mathrm{p}=0.021)$, while those who were obese were more likely to have heart problems $(\mathrm{p}=0.036)$. Those with a higher WHR were more likely to have heart problems $(\mathrm{p}=0.013)$. Other chronic conditions like Hypertension and diabetes were not significantly related to BMI and WHR (Table 3). There were no significant interactions found between the independent variables.

Obesity is now a days become a public health concern. Our analyses indicated that $40.0 \%$ of our sample population were obese and $39.2 \%$ were overweight. Obesity prevalence is higher in women aged 45 years and above than those aged 30-44 years. These percentages may vary from place to place, because obesity depends on many factors such as their food habits, lack of physical activity, genetic predisposition and so on ${ }^{[18-20]}$. The results documented that the high prevalence of heart problems among women who were overweight and obese, which shown by many studies ${ }^{[21,22]}$.

The prevalence of high WHR in our sample was $65.8 \%(n=79)$. Multiple logistic regressions showed that women who aged 45 years and above were more likely to have high WHR than those aged 30-44. Those with a higher WHR were more likely to have heart problems $(\mathrm{p}=0.013)$. Heart problems were higher among women have high WHR when compared to other categories. WHR is an indicator of central fat distribution and also a strong measure, assessing for risk of heart problems, diabetes and hypertension ${ }^{[23,24]}$ 
Table 1: Socio-demographic characteristics of sample by BMI category and WHR category.

\begin{tabular}{|c|c|c|c|c|c|c|c|}
\hline \multirow[t]{2}{*}{ Variable } & \multirow[t]{2}{*}{ Category } & \multicolumn{4}{|c|}{ BMI Category \% } & \multicolumn{2}{|c|}{ Waist-Hip Ratio \% } \\
\hline & & $\begin{array}{l}\text { Underweight } \\
(\mathrm{n}=3)\end{array}$ & $\begin{array}{l}\text { Normal weight } \\
(n=22)\end{array}$ & $\begin{array}{l}\text { Overweight } \\
(n=47)\end{array}$ & $\begin{array}{l}\text { Obese } \\
(n=48)\end{array}$ & $\begin{array}{l}\text { Low WHR } \\
(n=36)\end{array}$ & $\begin{array}{l}\text { High WHR } \\
(n=79)\end{array}$ \\
\hline Age Group & $30-44$ & 5.5 & 25.5 & 41.8 & 27.3 & 66.7 & 36.7 \\
\hline \multirow[t]{2}{*}{ (in years) } & $45-59$ & 0 & 10.6 & 42.6 & 46.8 & 30.6 & 43.0 \\
\hline & $60+$ & 0 & 16.7 & 22.2 & 61.1 & 2.8 & 20.3 \\
\hline \multirow[t]{4}{*}{ Marital Status } & Never Married & 0 & 21.4 & 42.9 & 35.7 & 22.2 & 24.1 \\
\hline & Married & 1.3 & 20.0 & 37.5 & 41.3 & 66.7 & 67.1 \\
\hline & Widowed & 10.0 & 0 & 50.0 & 40.0 & 8.3 & 8.9 \\
\hline & Divorced/Separated & 50.0 & 0 & 0 & 50.0 & 2.8 & 0 \\
\hline \multirow[t]{4}{*}{ Education } & None & 5.3 & 10.5 & 42.1 & 42.1 & 13.9 & 17.7 \\
\hline & Primary (Basic) & 0 & 12.5 & 37.5 & 50.0 & 2.8 & 7.6 \\
\hline & Secondary & 0.0 & 30.8 & 30.8 & 38.5 & 11.1 & 10.1 \\
\hline & Completed & 2.5 & 18.8 & 40.0 & 38.8 & 72.2 & 64.6 \\
\hline \multirow[t]{4}{*}{ Employment Status } & Homemaker & 3.8 & 15.4 & 42.3 & 38.5 & 19.4 & 22.8 \\
\hline & Employed & 2.7 & 21.6 & 40.5 & 35.1 & 63.9 & 59.5 \\
\hline & Unemployed & 0.0 & 13.3 & 33.3 & 53.3 & 13.9 & 12.7 \\
\hline & Retired & 0.0 & 0.0 & 20.0 & 80.0 & 2.8 & 5.1 \\
\hline \multirow[t]{2}{*}{ Hypertension } & No & 66.7 & 72.7 & 85.1 & 56.3 & 75.0 & 69.6 \\
\hline & Yes & 33.3 & 27.3 & 14.9 & 43.8 & 25.0 & 30.4 \\
\hline \multirow[t]{2}{*}{ Heart Problems } & No & 100.0 & 100.0 & 95.7 & 95.8 & 100.0 & 94.9 \\
\hline & Yes & 0.0 & 0.0 & 4.3 & 4.2 & 0.0 & 5.1 \\
\hline \multirow[t]{2}{*}{ Diabetes } & No & 100.0 & 81.8 & 80.9 & 72.9 & 77.8 & 78.5 \\
\hline & Yes & 0.0 & 18.2 & 19.1 & 27.1 & 22.2 & 21.5 \\
\hline
\end{tabular}

Table 2: Prevalence (95 \% CI) of BMI and High WHR Categories by socio demographic characteristics.

\begin{tabular}{|c|c|c|c|c|c|c|c|c|c|}
\hline \multirow[t]{2}{*}{ Variable } & \multicolumn{6}{|l|}{ BMI } & \multicolumn{3}{|l|}{ High WHR } \\
\hline & $\begin{array}{l}\text { Overweight } \\
\text { Odds Ratio }\end{array}$ & $(95 \%$ CI $)$ & P Value & $\begin{array}{l}\text { Obese } \\
\text { Odds Ratio }\end{array}$ & $(95 \% \mathrm{CI})$ & P Value & Odds Ratio & $(95 \%$ CI $)$ & P Value \\
\hline $\begin{array}{l}\text { Age Group (in years) } \\
30-44\end{array}$ & 1 (reference) & & & 1 (reference) & & & 1 (reference) & & \\
\hline
\end{tabular}




\begin{tabular}{|c|c|c|c|c|c|c|c|c|c|}
\hline $45-59$ & 1.65 & $(1.03,2.63)$ & 0.036 & 0.82 & $(0.67,0.99)$ & 0.046 & 1.15 & $(1.01,1.30)$ & 0.048 \\
\hline $\begin{array}{l}60+ \\
\text { Marital Status }\end{array}$ & 1.57 & $(1.01,3.47)$ & 0.043 & 0.74 & $(0.56,0.98)$ & 0.038 & 1.20 & $(1.08,1.41)$ & 0.040 \\
\hline Never Married & 1.03 & $(0.65,1.66)$ & 0.891 & 1.15 & $(1.05,1.39)$ & 0.152 & 0.99 & $(0.91,1.07)$ & 0.763 \\
\hline Widowed & 0.98 & $(0.50,1.90)$ & 0.908 & 0.90 & $(0.62,1.30)$ & 0.570 & 0.99 & $(0.87,1.12)$ & 0.871 \\
\hline Divorced/Separated & - & - & - & 0.97 & $(0.52,1.82)$ & 0.971 & - & - & - \\
\hline $\begin{array}{l}\text { Married } \\
\text { Education }\end{array}$ & 1 (reference) & & & 1 (reference) & & & 1 (reference) & & \\
\hline None & 2.44 & $(1.17,5.09)$ & 0.018 & 0.87 & $(0.67,1.34)$ & 0.306 & 1.04 & $(0.96,1.14)$ & 0.307 \\
\hline Primary (Basic) & 2.59 & $(1.02,8.11)$ & 0.034 & 1.04 & $(0.80,1.37)$ & 0.756 & 0.97 & $(0.83,1.13)$ & 0.701 \\
\hline Secondary & 1.71 & $(0.75,3.89)$ & 0.205 & 0.98 & $(0.75,1.28)$ & 0.879 & 1.01 & $(0.90,1.13)$ & 0.877 \\
\hline $\begin{array}{l}\text { Completed } \\
\text { Employment Status }\end{array}$ & 1 (reference) & & & 1 (reference) & & & 1 (reference) & & \\
\hline Unemployed & 1.08 & $(0.55,2.12)$ & 0.817 & 0.94 & $(0.75,1.18)$ & 0.613 & 0.97 & $(0.87,1.09)$ & 0.642 \\
\hline Homemaker & 1.35 & $(0.81,2.24)$ & 0.250 & 0.87 & $(0.69,1.10)$ & 0.250 & 1.01 & $(0.94,1.10)$ & 0.715 \\
\hline Retired & 1.74 & $(1.34,8.86)$ & 0.024 & 0.88 & $(0.63,1.24)$ & 0.468 & 0.93 & $(0.75,1.14)$ & 0.462 \\
\hline Employed & 1 (reference) & & & 1 (reference) & & & 1 (reference) & & \\
\hline
\end{tabular}

Table (3): Prevalence (95 \% CI) of Chronic Health Conditions by BMI and WHR characteristics.

\begin{tabular}{|c|c|c|c|c|c|c|c|c|c|c|}
\hline \multicolumn{2}{|c|}{ Chronic Health Conditions } & \multicolumn{6}{|l|}{ BMI } & \multirow{2}{*}{\multicolumn{3}{|c|}{ High WHR }} \\
\hline & & Overweight & & & Obese & & & & & \\
\hline \multirow[b]{2}{*}{ Hypertension } & & Odds Ratio & $(95 \% \mathrm{CI})$ & P Value & Odds Ratio & $(95 \% \mathrm{CI})$ & P Value & Odds Ratio & $(95 \% \mathrm{CI})$ & P Value \\
\hline & Yes & 1(reference) & & & 1(reference) & & & 1(reference) & & \\
\hline \multirow{3}{*}{ Heart Problems } & No & 0.75 & $(0.41,1.40)$ & 0.342 & 0.90 & $(0.76,1.06)$ & 0.219 & 0.947 & $(0.88,1.02$ & 0.146 \\
\hline & Yes & 1(reference) & & & 1(reference) & & & 1(reference) & & \\
\hline & No & 0.33 & $(1.06,1.87)$ & 0.021 & 1.55 & $(1.12,3.36)$ & 0.036 & 1.193 & $(1.12,1.55)$ & 0.013 \\
\hline \multirow[t]{2}{*}{ Diabetes } & Yes & 1(reference) & & & 1(reference) & & & 1(reference) & & \\
\hline & No & 1.14 & $(0.68,1.91)$ & 0.612 & 0.87 & $(0.43,1.04)$ & 0.121 & 0.999 & $(0.92,1.08)$ & 0.973 \\
\hline
\end{tabular}


This study may have some limitations in data gathering like all cross-sectional studies. It is imperative that strategies be developed to identify, treat, and ultimately prevent obesity. In the coming years new management and therapeutic strategies for obesity will likely emerge.

\section{CONCLUSION}

BMI, WHR are important predictors of heart problems and provides high association of risk factors in an elderly population. Assessing these predictors will help reducing the incidence of heart problems, hypertension and diabetes. Further research with particular focus on the association of obesity and some diseases in women is highly recommended.

\section{REFERENCES}

1. World Health Organization. Preventing and Managing the global epidemic. Geneva1998, Switzerland, obesity RoaWco.

2. World Health Organization. Physical Status: The Use of and Interpretation of Anthropometry, WHO technical report series no. 854. Geneva-2011: Report of WHO Expert Committee; 36.

3. Buffa R, Floris G, Lodde M, Cotza M, Marini E. Nutritional status in the healthy longeval population from Sardinia (Italy). J Nutr Health Aging. 2010; 14(2): 97-102.

4. Restria Fauziana, Anitha Jeyagurunathan , Edimansyah Abdin, Janhavi Vaingankar, Vathsala Sagayadevan, Saleha Shafie, Rajeswari Sambasivam, Siow Ann Chong and Mythily Subramaniam. Body mass index, waist-hip ratio and risk of chronic medical condition in the elderly population: results from the Well-being of the Singapore Elderly (WiSE) Study. BMC Geriatrics. 2016; 16:125, 1-9. DOI 10.1186/s12877-0160297-z.

5. Dey D K, Rothenberg E, Sundh V, Bosaeus I, Steen B. Height and body weight in the elderly. I. A 25-year longitudinal study of a population aged 70 to 95 years. Eur J Clin Nutr.1999; 53 (12): 905-14.

6. Steen B. Body composition and Aging. Nutr Rev. 1988; 46(2):45-51. doi:10.1111/j.1753-4887.1988.tb05386.x.

7. Schwartz A V, Kelsey J L, Sidney S, Grisso J A. Characteristics of falls and risk of hip fracture in elderly men. Osteoporos Int. 1998; 8 (3): 240-6. doi:10.1007/ s001980050060.

8. Goh L G, Dhaliwal S S, Welborn T A, Lee A H, Della P R. Anthropometric measurements of general and central obesity and the prediction of cardiovascular disease risk in women: a cross-sectional study. BMJ open. 2014; 4(2):e004138. doi:10.1136/bmjopen-2013-004138. 
9. Whitehead C, Finucane P. Malnutrition in elderly people. Aust N Z J Med. 1997; 27:68-74. doi:10.1111/j.1445-5994.1997.tb00917.x.

10. Santos J L, Albala C, Lera L, Garcia C, Arroyo P, Perez-Bravo F, et al. Anthropometric measurements in the elderly population of Santiago, Chile. Nutrition. 2004; 20 (5): 452-7. doi:10.1016/j.nut.2004.01.010.

11. Danaei G, Pan A, Hu F B, Hernan M A. Hypothetical midlife interventions in women and risk of type 2 diabetes. Epidemiology. 2013; 24(1):122-8.doi:10.1097/EDE. 0b013e318276c98a.

12. Woo J, Ho S C, Yuen Y K, Yu L M, Lau J. Cardiovascular risk factors and 18-month mortality and morbidity in an elderly Chinese population aged 70 years and over. Gerontology. 1998; 44(1): 51-5.

13. National Heart, Lung, and Blood Institute (NHLBI), North American Association for the Study of Obesity (NAASO). The Practical Guide: Identification, Evaluation, and Treatment of Overweight and Obesity in Adults (No 00-4084). 2000. Rockville: National Institutes of Health.

14. Centre for Public Health Excellence at NICE (UK, and National Collaborating Centre for Primary Care) UK. (2006). "Obesity: the prevention, identification, assessment and management of overweight and obesity in adults and children".

15. Janssen I, Katzmarzyk P T, Ross R. Body mass index, waist circumference, and health risk: evidence in support of current National Institutes of Health guidelines. Arch Intern Med. 2002; 162 (18): 2074-9.

16. Ardern C I, Katzmarzyk P T, Janssen I, Ross R. Discrimination of health risk by combined body mass index and waist circumference. Obes Res. 2003; 11(1):135-42. doi: 10.1038/oby.2003.22.

17. Chan J M, Rimm E B, Colditz G A, Stampfer M J, Willett W C. Obesity, fat distribution, and weight gain as risk factors for clinical diabetes in men. Diabetes Care. 1994;17(9):961-9.

18. World Health Organization. Waist Circumference and Waist-hip Ratio: Report of a WHO Expert Consultation, Geneva 8-11December 2008, World HealthOrganization2011.http://www.who.int/nutrition/publications/obesity/WHO_rep ort_waistcircumferec_and_waisthip_ratio/en/. Accessed Nov 2014.

19. Bloomgarden Z T. Prevention of obesity and diabetes. Diabetes Care. 2003; 1; 26 (11): 3172-8.

20. Kapoor S. Blood pressure, waist to hip ratio and body mass index among affluent Punjabi girls of Delhi. Acta Medica Auxologica. 2000; 32 (3): 153-8. 
21. Okosun I S, Prewitt T E, Cooper R S. Abdominal obesity in the United States: prevalence and attributable risk of hypertension. Journal of human hypertension. 1999; 1;13 (7): 425-30.

22. Ferguson T S, Younger N O, Tulloch-Reid M K, Wright M B, Ward E M, Ashley D E, Wilks R J. Prevalence of prehypertension and its relationship to risk factors for cardiovascular disease in Jamaica: analysis from a cross-sectional survey. BMC Cardiovascular Disorders. 2008; 28; 8 (1): 20.

23. Schmidt M I, Duncan B B, Canani L H, Karohl C, Chambless L. Association of waisthip ratio with diabetes mellitus: strength and possible modifiers. Diabetes care. 1992; 1;15 (7): 912-4.

24. Grievink L, Alberts J F, O'niel J, Gerstenbluth I. Waist circumference as a measurement of obesity in the Netherlands Antilles; associations with hypertension and diabetes mellitus. European journal of clinical nutrition. 2004; 1;58(8):1159-65.

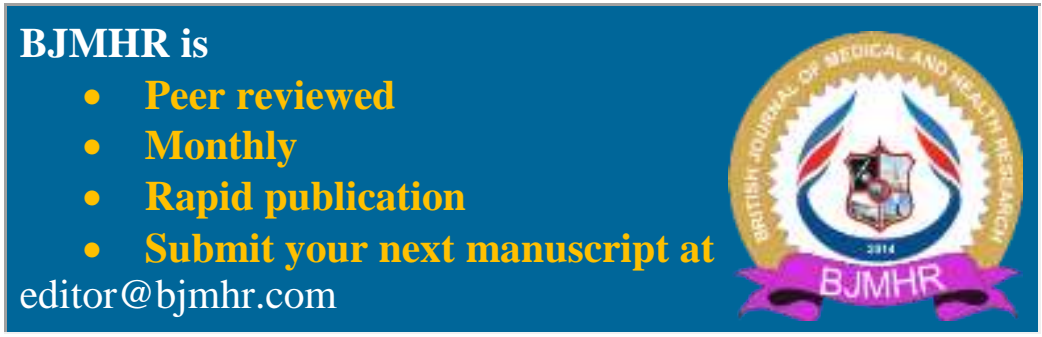

